\title{
REVIEW
}

\section{Pre-historic eating patterns in Latin America and protective effects of plant-based diets on cardiovascular risk factors}

\author{
Julio C. Acosta Navarro,' Silvia M. Cárdenas Prado," Pedro Acosta Cárdenas,'" Raul D. Santos,' Bruno Caramelli' \\ 'Heart Institute (InCor), Faculdade de Medicina, Universidade de São Paulo, São Paulo, SP, Brazil. "Psychiatric Institute, Faculdade de Medicina,
} Universidade de São Paulo, SP, Brazil. "' Anhembi-Morumbi University, Medical School, São Paulo, SP, Brazil.

In this review, we present the contributions to nutrition science from Latin American native peoples and scientists, appreciated from a historic point of view since pre-historic times to the modern age. Additionally, we present epidemiological and clinical studies on the area of plant-based diets and their relation with the prevention and treatment of cardiovascular diseases conducted in recent decades, and we discuss challenges and perspectives regarding aspects of nutrition in the region.

KEYWORDS: Vegetarianism; Latin America; Cardiovascular disease; Diet; Indians.

Navarro JCA, Prado SMC, Cardenas PA, Santos RD, Caramelli B. Pre-historic eating patterns in Latin America and protective effects of plant-based diets on cardiovascular risk factors. Clinics. 2010;65(10):1049-1054.

Received for publication on May 16, 2010; First review completed for June 13, 2010; Accepted for publication on July 13, 2010

E-mail: jnavarro_2@hotmail.com

Tel.: 5511 3069-5299

\section{INTRODUCTION}

This review has two objectives. First, we reviewed the native Latin American pattern of eating from a historical standpoint. The second objective is to present epidemiological and clinical studies on the area of plant-based diets and their relation with the prevention and treatment of cardiovascular diseases conducted in recent decades, and we discuss challenges and perspectives in the region.

Native people from Latin America have various ethnic origins and high rates of internal migration. Immigrants from Europe, Asia, and Africa in several waves also have contributed to define communities with an original profile, not only in terms of genetics but also with respect to nutritional habits and lifestyles. This is the reason for the importance of research among these people. ${ }^{1}$

Recent clinical data on this subject were collected by means of multiple PubMed and Science Direct library searches, bibliography cross-referencing of all articles, and previous review articles spanning the period from 1960 to 2009. Keywords including "plant-based diets," "Latin American diets," "vegetarianism," and "cardiovascular disease" were used in various combinations. Relevant study differences were included in this review.

\section{Pre-historic eating patterns in Latin America}

Current scientific evidence gives us insight into the food habits of ancient Americans, which apparently varied. A

\footnotetext{
Copyright (c) 2010 CLINICS - This is an Open Access article distributed under the terms of the Creative Commons Attribution Non-Commercial License (http:// creativecommons.org/licenses/by-nc/3.0/) which permits unrestricted noncommercial use, distribution, and reproduction in any medium, provided the original work is properly cited.
}

Paleoindian campsite uncovered in stratified pre-historic deposits in the Caverna da Pedra Pintada at Monte Alegre in the Brazilian Amazon indicated a late Pleistocene age contemporary with North American Paleoindians. Paintings, triangular bifacial spear points, and other tools in the cave documented a culture distinct from North American ones. Carbonized tree fruits and wood and faunal remains reveal a broad-spectrum economy of humid tropical forest and riverine foraging based on gathering fruit and nuts, fishing, and hunting small animals rather than felling mammoths. ${ }^{2}$

On the other hand, scientists say that they have definitive proof that pre-historic Indians in the Southwest (Anasazi population) not only killed, butchered, and cooked but actually ate other human beings The evidence is in the form of a dried chunk of human excrement, or coprolite, containing a telltale human protein that could have gotten there only by being ingested. ${ }^{3}$

The first reports on the Mesoamerican diet before the Spanish conquest led contemporary Europeans to believe that "the style of life is so frugal that the hermits in the desert could not live with more sobriety." New light was shed on the matter in Oviedo's work in 1528 with the first analytical descriptions of the wealth and variety of New World foods: staples made of corn and yucca flours, many types of beans, pineapples, and other tropical fruits. Oviedo points out the distinction between tubers and yams and sweet potatoes, as well as the importance of aji, or chili peppers, which the natives used to flavor corn, meat, and fish. Recent studies on the inhabitants of the low plains, the Mayas, have concluded that during the Neolithic formative period (the fourth to third millennia B.C.), these people were skillful in selecting and handing down the crops that were vital for their survival. The most important was corn. Indeed, the Maya called it "ishin," which mean "center" - a 
symbolic double meaning signifying its critical role in differentiating populations that subsisted principally on agriculture from those that subsisted by hunting and gathering. Adams has shown that the intake of corn in the present Mayan diet is equal to $2500 \mathrm{kcal} /$ day per person. If this is comparable to the consumption of the ancient Maya, their primitive agricultural system was, in fact, highly specialized to provide sufficient food for the calculated density of the population. Corn was the staple, but they also ate a variety of other foods. The Maya had domesticated fruits and vegetables such as the anone, avocado, tuayaba, passion fruit, zucchini, tomatoes, carrots, beans, and sweet potatoes. This diet of fruit and vegetables was complemented by fishing and hunting and by domesticated food animals, including turkeys and dogs (which were eaten during special feasts or during famines). ${ }^{4}$

On the other hand the pre-Incas took advantage of the geography of coast Peruvian and built irrigation channels leading to duplication of the cultured area. A great network of channels was built transporting water through the valley of Moche. Richard Leakey thinks that Moche boasted the most advanced agriculture in the world ${ }^{5}$. The potato (Solanum tuberosum) is native to the Andes and dates back 7000 years before the pre-Inca and Inca civilizations. It played an important role in the pre-Hispanic diet. The potato is a good source of protein, carbohydrates, iron, magnesium, potassium, and $B$ and $C$ vitamins. Historian Espinoza Soriano thinks that thanks to the potato, there was no nutritional deficiency in the Andean population. ${ }^{6}$ At present, it is clear that good nutritional status depends on several factors, including meeting optimal requirements from all nutrients, so despite the fact that the potato is rich in carbohydrates, vitamins, and minerals, it should be complemented with other foods.

The means of subsistence of Peruvians were very restricted. On the coast, fish accounted for, naturally, a great portion of the diet, but on the plateau, it was very rare because the rivers are too torrential to permit its existence. The available food, then, consisted mainly of vegetables. At the end of the seventeenth century, Del Hoyo ${ }^{7}$ observed that the Peruvian Indians ate little meat in several regions. Long after the arrival of the Spaniards, the Indians did not use more than the leather and fat of cattle imported from Europe, without consuming meat. Garcilaso enumerated all lacking things among Peruvians, noting a long list of foods. ${ }^{8}$

\section{Protective effects of plant-based diets on cardiovascular risk factors}

In 1964, Dante Pazzanese et al. ${ }^{9}$ evaluated 53 Indians with a predominantly vegetarian (VEG) diet and a high level of physical activity living in a central region of Brazil. In clinical, electrocardiographical, and laboratory exams, the authors observed very low values for serum lipids and no evidence of clinical atherosclerosis. In 1966, Faro Netto et al. $^{10}$ also observed lower levels of LDL-C (low-densitylipoprotein cholesterol) in 53 natives of the Xingu River jungle with a predominantly VEG diet and a high level of physical activity. In 1968, Ruiz and Peñaloza ${ }^{11}$ reported on the blood pressure of Peruvian highlanders with a predominantly VEG diet. They observed lower levels of blood pressure compared to coastal individuals.

The Tarahumara Indians from Mexico have attracted special medical attention because of their remarkable physical endurance and their diet, which contains very little food from animal sources. They inhabit the rugged Sierra Madre Occidental Mountains in the north-central state of Chihuahua, Mexico. Members of this tribe have an exceptional capacity for exercise. ${ }^{12,13}$ Scattered anthropological reports suggest that the diet of the Tarahumaras consists primarily of beans, corn, and squash. ${ }^{12,14}$ Connor, ${ }^{15}$ evaluating 523 healthy Tarahumara, observed cholesterol intake to be $72 \mathrm{mg} /$ day, while fat comprised only $12 \%$ of total calories. The mean plasma total cholesterol (TC) was $125 \mathrm{mg}$, and triglyceride was (TG) $120 \mathrm{mg} / \mathrm{dl}$. They showed an excellent correlation between intake of cholesterol from 20 to $150 \mathrm{mg} / \mathrm{dl}$ and TC levels. Adult Tarahumara have low plasma TC levels, averaging $136 \mathrm{mg} / \mathrm{dl}^{16}{ }^{16} \mathrm{In}$ another study, the same authors enrolled eight Tarahumara men in a cholesterol-feeding experiment with two dietary periods of 3 weeks: first a baseline, cholesterol-free diet followed by a second one containing $1000 \mathrm{mg}$ of cholesterol provided in the form of egg yolk. Other than different cholesterol content, the diets were identical, with the bulk of calories derived from corn and beans. Plasma cholesterol level increased from 113 to $134 \mathrm{mg} / \mathrm{dl}$ after feeding dietary cholesterol; LDL-C rose similarly. This net increase of $34 \mathrm{mg} / \mathrm{dl}$, or $30 \%$, in plasma cholesterol was, roughly, similar to the changes already described in normocholesterolemic U.S. subjects having a different dietary background. ${ }^{17}$

In 1990, Mancilha-Carvalho and Crews ${ }^{18}$ conducted a study with Yanomami Indians. That population has quite a different lifestyle from individuals living in the industrialized world. Their diet is based on local agriculture, including roots, sweet potato, and sugar cane, with the addition of wild fruits and insects. The Yanomami do not raise animals, and the meat they include in their diet comes from hunting; therefore, it is relatively rare. They have little access to processed sugar, salt, alcohol, milk and its byproducts, and eggs. In the study, the lipid profile of Brazilian Yanomamis was compared to that of American men from studies such as the National Health and Nutrition Examination Survey-1976-80 (NHANES) and the Lipid Research Clinics Population (LRC). When compared to Americans in the NHANES study, the Yanomamis reported lower TC serum levels compared to Americans - both males and females. When compared to Americans in the LRC study, the Yanomamis were found to have lower TC, LDL-C, and HDL-C (high-density-lipoprotein cholesterol) levels - also in both males and females.

The Pima Indians of Arizona have the highest reported prevalence of obesity and type 2 diabetes. In parallel with abrupt changes in lifestyle, these prevalences in the Arizona Pimas have increased to epidemic proportions during recent decades. To assess the possible impact of the environment on the prevalence of obesity and type 2 diabetes, Ravussin et al. ${ }^{19}$ collected data on members of a population with Pima ancestry (separation 700-1000 years ago) living in a remote, mountainous location in northwestern Mexico, with a lifestyle contrasting markedly with that in Arizona. They observed that obesity and, perhaps, type 2 diabetes are less prevalent among people of Pima heritage living a "traditional" lifestyle than among Pima living in an "affluent" environment. The authors suggest that, despite a similar potential genetic predisposition for metabolic health conditions, a traditional lifestyle, characterized by a diet including less animal fat and more complex carbohydrates and by greater energy expenditure in physical labor, may protect 
against the development of cardiovascular disease risk factors, obesity, and type 2 diabetes.

In the Lima Study, 20,21 we analyzed the relationship between type of diet and cardiovascular disease risk factors among vegetarians (VEG), semi-vegetarians (SVEG), and omnivorous (OMN) Peruvian subjects with ethnographic characteristics of mixed Spanish and indigenous descent. In Phase 1, measured blood pressure (BP) and body mass index (BMI) were measured from 105 VEGs, 34 SVEGs, and 45 OMNs. Phase 2 compared laboratory parameters among 38 VEGs, 15 SVEGs, and 31 OMNs. The main results were: 1) there was no difference in BP average among the groups: $111 / 70$ for VEGs, $113 / 70$ for SVEGs, and 115/70 $\mathrm{mmHg}$ for OMNs ( $p>0.05) ; 2)$ only $2.9 \%$ of the VEGs were confirmed to be hypertensive compared with $13.3 \%$ of the OMNs $(\mathrm{p}<0.05) ; 3)$ body weight average and BMI were lower among VEGs (57.6 kg and 23.7) and SVEGs (58.4 kg and 23.7) compared with OMNs $(64.4 \mathrm{~kg}$ and 26.5) $(\mathrm{p}<0.05)$; 4) serum cholesterol average was lower among VEGs (190 mg/dl) compared with OMNs (213 mg/dl), though the difference was not significant $(\mathrm{p}=0.08)$; 5$)$ the CT and HDL index averages were lower among SVEGs and VEGs (4.4 and 4.7, respectively) compared with the OMNs (5.6) $(p<0.05) ; 6)$ the LDL and HDL index averages were lower among SVEGs and VEGs (both 3.0) compared with the OMNs (3.7) $(p<0.05)$. Based on these findings, we concluded that VEG subjects are exposed to a lesser degree of cardiovascular risk factors when compared to OMNs, while the SVEG are at an intermediate level of exposure.

In Chile, Mezzano et al. ${ }^{22}$ studied haemostatic and inflammatory cardiovascular risk factors (CVRF) and total plasma homocysteine (tHcy) in 26 VEGs (23 lacto or lactoovo vegetarians and 3 vegans), matched by age, sex, and socioeconomic status with OMN controls. VEGs had significantly lower proportion of eicosapentaenoic (EPA) and docosahexaenoic (DHA) acids in plasma lipids, significantly shortened bleeding time, and increased blood platelet count and in-vitro platelet function (aggregation and secretion). Plasma levels of all coagulation or fibrinolytic factors and natural inhibitors synthesized in the liver were lower in vegetarians than in controls. Whereas for some factors this decrease was statistically significant (fibrinogen, factor VIIc, antithrombin III, protein S, and plasminogen) for the remaining factors (VIIIc, Vc, prothrombin, and protein $\mathrm{C}$ ), a trend in the same direction was found. For haemostatic proteins of predominantly extrahepatic origin (von Willebrand factor, tPA, PAI-1) this tendency was not present. No significant differences in inflammatory proteins (C-reactive protein and alpha1-protease inhibitor) were detected in either group. tHcy was significantly increased in VEGs and correlated only with cobalamin levels. Mezzano suggested that the increased platelet function and tHcy found in vegetarians may counteract the known cardiovascular health benefits of the VEG diet.

In the São Paulo Study, ${ }^{23}$ we compared the prevalence of cardiovascular risk factors among VEG $(n=65)$, SVEG $(n=30)$ and $\mathrm{OMN}(\mathrm{n}=41)$ subjects. One hundred thirty-six of 1,345 volunteers from the Adventist Church of São Paulo met the inclusion criteria and were divided into 3 groups. Electrocardiogram findings, blood pressure, blood lipids, glucose, and anthropometric data were evaluated and compared. There was no difference in the prevalence of anemia or overt nutritional deficiency, but there was a difference in nutrient intake among the groups (Table 1). Therefore, in spite of a respectable homogeneity among the subjects, our study showed that VEGs exhibited a significantly lower mean systolic and diastolic blood pressure, lower prevalences of arterial hypertension and hypercholesterolemia, and lower

Table 1 - Distribution of anthropometric indicators and nutrient intake.*

\begin{tabular}{|c|c|c|c|c|}
\hline Group/IndicatorNutrient & $\begin{array}{c}\text { VEG } \\
n=65\end{array}$ & $\begin{array}{l}\text { SVEG } \\
n=30\end{array}$ & $\begin{array}{l}\text { OMN } \\
N=41\end{array}$ & $P$ value \\
\hline Age $(y)$ & $34.74 \pm 8.92$ & $36.07 \pm 9.93$ & $33.90 \pm 10.56$ & 0.65 \\
\hline Weight (kg) & $65.61 \pm 13.51$ & $71.14 \pm 13.77$ & $67.01 \pm 12.66$ & 0.17 \\
\hline Height $(\mathrm{cm})$ & $163.81 \pm 9.73$ & $165.65 \pm 9.72$ & $163.09 \pm 9.05$ & 0.54 \\
\hline BMI $(\mathrm{kg} / \mathrm{m} 2)$ & $24.47 \pm 4.66$ & $25.86 \pm 19.34$ & $25.13 \pm 3.85$ & 0.34 \\
\hline Triceps-skinfold (mm) & $23.31 \pm 9.84$ & $25.97 \pm 7.05$ & $23.20 \pm 9.26$ & 0.36 \\
\hline Abdominal-skinfold (mm) & $27.48 \pm 12.28$ & $30.2 \pm 9.54$ & $25.22 \pm 9.20$ & 0.16 \\
\hline Waist $(\mathrm{cm})$ & $81.45 \pm 13.32$ & $83.77 \pm 11.42$ & $81.22 \pm 11.93$ & 0.65 \\
\hline Hip (cm) & $98.72 \pm 9.46$ & $102.93 \pm 7.66$ & $98.03 \pm 11.82$ & 0.09 \\
\hline Energy (kcalories) & $1,472.1 \pm 652 *$ & $1,592.9 \pm 613$ & $1,810.45 \pm 768 \dagger$ & $* \dagger p=0.048$ \\
\hline Proteins (\% kcal) & 12.40 * & $17.06+$ & $16 . \overline{19} \dagger$ & $* \dagger p<0.001$ \\
\hline Carbohydrate (\% kcal) & 63.57 * & 57.80 & $52.60 \dagger$ & $* \dagger p<0.000$ \\
\hline Fat (\% kcal) & $24.01 *$ & 25.13 & $31.20+$ & $* \dagger p=0.004$ \\
\hline Saturated fat (\% kcal) & 11.33 * & $13.15 \dagger$ & $21.60 \ddagger$ & $\begin{array}{l}* \dagger p=0.003 \\
*+p<0.001\end{array}$ \\
\hline Polyunsaturated fat (\% kcal) & 4.65 & 5.15 & 5.13 & 0.912 \\
\hline Monounsaturated fat (\% kcal) & 7.66 & $5.81 *$ & $10.3 \dagger$ & $* \dagger p=0.040$ \\
\hline $\mathrm{P}: \mathrm{S}$ ratio & $0.63 \pm 0.81 *$ & $0.43 \pm 0,36 \dagger$ & $0.32 \pm 0.40 *$ & $\begin{array}{l}* \dagger p=0.018 \\
* \leftarrow p=0.008\end{array}$ \\
\hline Cholesterol (mg) & $67.81 \pm 82.81 *$ & $131.34 \pm 84.66 \dagger$ & $253.17 \pm 193.6 *$ & $\begin{array}{l}*+p<0.001 \\
\dagger p=0.001\end{array}$ \\
\hline Calcium (mg) & $644.21 \pm 367$ & $619.21 \pm 307$ & $687.61 \pm 435$ & 0.735 \\
\hline Iron (mg) & $11.54 \pm 6.93$ & $11.14 \pm 5.05$ & $13.59 \pm 9.29$ & 0.283 \\
\hline Zinc (mg) & $4.0 \pm 3.82$ * & $4.9 \pm 3.72 \dagger$ & $9.18 \pm 6.43 t$ & $\begin{array}{l}*+p<0.001 \\
\dagger+p=0.001\end{array}$ \\
\hline Vitamin C (mg) & $143.86 \pm 103$ & $108.16 \pm 97.4$ & $115.67 \pm 135$ & 0.263 \\
\hline
\end{tabular}

${ }^{*}$ Means are shown \pm standard deviation. Means with different signs are different from each other; $p<0.05$ (Scheffe's test for ANOVA) NS = not significant; VEG = vegetarians; SVEG = semi-vegetarians; OMN = omnivorous. 
Table 2 - Blood pressure, lipids, glucose, and prevalence of arterial hypertension, metabolic syndrome, and hypercholesterolemia by dietary group.

\begin{tabular}{|c|c|c|c|c|}
\hline Group & VEG $n=65$ & SVEG $n=30$ & OMN N = 41 & $\mathrm{p}$ value \\
\hline Diastolic blood pressure $(\mathrm{mmHg})$ & $71.78 \pm 7.19 *$ & $78.73 \pm 7.05 \dagger$ & $80.98 \pm 10.69 *$ & $\begin{array}{l}* \dagger p=0.004 \\
* \$ p<0.001\end{array}$ \\
\hline Systolic blood pressure $(\mathrm{mmHg})$ & $109.45 \pm 10.99 *$ & $116.1 \pm 13.39 \dagger$ & $121.44 \pm 13.0 \ddagger$ & $\begin{array}{l}* t p=0.050 \\
* \quad p<0.001\end{array}$ \\
\hline Glucose (mg/dL) & $79.49 \pm 8.71$ & $77.3 \pm 7.26$ & $83.93 \pm 17.89$ & 0.056 \\
\hline Total cholesterol $(\mathrm{mg} / \mathrm{dL})(\mathrm{mmol} / \mathrm{l})$ & $\begin{aligned} 167.54 & \pm 33.32^{*} \\
4.33 & \pm 0.86\end{aligned}$ & $\begin{array}{r}173.83 \pm 9.11 \\
4.50 \pm 0.75\end{array}$ & $\begin{aligned} 188.80 & \pm 33.59 \dagger \\
4.88 & \pm 0.87\end{aligned}$ & 0.006 \\
\hline LDL-C (mg/dL) (mmol/l) & $\begin{aligned} 92.72 & \pm 29.05 * \\
2.40 & \pm 0.75\end{aligned}$ & $\begin{aligned} 98.13 & \pm 22.67 \\
2.54 & \pm 0.59\end{aligned}$ & $\begin{aligned} 107.49 & \pm 29.82 \dagger \\
2.78 & \pm 0.77\end{aligned}$ & 0.033 \\
\hline $\mathrm{HDL}-\mathrm{C}(\mathrm{mg} / \mathrm{dL})(\mathrm{mmol} / \mathrm{l})$ & $\begin{array}{c}54.95 \pm 11.21 \\
1.42 \pm 0.29\end{array}$ & $\begin{array}{l}56.6 \pm 12.19 \\
1.46 \pm 0.32\end{array}$ & $\begin{array}{c}59.32 \pm 15.13 \\
1.53 \pm 0.39\end{array}$ & 0.231 \\
\hline VLDL-C (mg/dL) (mmol/l) & $\begin{array}{c}19.86 \pm 12.34 \\
0.51 \pm 0.32\end{array}$ & $\begin{array}{l}19.1 \pm 10.90 \\
0.49 \pm 0.28\end{array}$ & $\begin{array}{l}22.0 \pm 22.31 \\
0.57 \pm 0.58\end{array}$ & 0.706 \\
\hline Triglycerides $(\mathrm{mg} / \mathrm{dL})(\mathrm{mmol} / \mathrm{l})$ & $\begin{array}{c}98.97 \pm 61.73 \\
2.56 \pm 1.6\end{array}$ & $\begin{array}{c}95.93 \pm 54.42 \\
2.56 \pm 1.41\end{array}$ & $\begin{array}{c}110.37 \pm 111.74 \\
2.85 \pm 2.88\end{array}$ & 0.694 \\
\hline TC/HDL-C ratio & $3.16 \pm 0.83$ & $3.16 \pm 0.67$ & $3.32 \pm 0.81$ & 0.538 \\
\hline LDL-C/HDL-C ratio & $1.76 \pm 0.66$ & $1.80 \pm 0.49$ & $1.90 \pm 0.65$ & 0.547 \\
\hline Arterial hypertension $(\geq 140 / 90 \mathrm{mmHg}) \%$ & $0.0^{*}$ & $10.0 \dagger$ & 21.95 & $\begin{array}{l}* \dagger p=0.29 \\
* \quad p<<0.001\end{array}$ \\
\hline Metabolic syndrome $\%$ & 3.1 & 3.3 & 9.8 & 0.271 \\
\hline Hypercholesterolemia (TC>200mg/dl) \% & 2.2 * & 1.7 * & $4.1 \dagger$ & $* \mathrm{p}<0.05$ \\
\hline
\end{tabular}

Means and percentages with different signs are significantly different from each other; $p<0.05$ (Scheffe's test for ANOVA for means and Fisher's exact test for percentages). VEG = vegetarians, SVEG = semi-vegetarians, OMN= omnivorous; HDL-C = high-density-lipoprotein cholesterol; LDL-C=low-densitylipoprotein cholesterol; VLDL-C=very low-density-lipoprotein cholesterol; TC=total cholesterol.

plasma concentrations of total cholesterol and LDL-C compared to OMN.

The SVEG group showed values intermediate between the VEG and OMN groups with respect to systolic and diastolic blood pressure, plasma concentrations of total cholesterol, and LDL-C, as well as lower prevalences of arterial hypertension and hypercholesterolemia compared to OMNs (Table 2).

In men, the average risk estimation of coronary heart disease (CHD) over a period of 10 years using the TC-based Framingham score index was statistically lower in VEGs than in OMNs (Table 3). Thus, in accordance with the previous data from Peruvians, our study indicated that a VEG diet and, to a lesser extent, the SVEG diet are associated with a better CHD risk profile.
In our two studies ${ }^{20,21,23,24}$ VEGs subjects showed fewer cardiovascular risk factors compared to SVEGs subjects and, additionally, these SVEGs showed a better profile of protection compared to OMN subjects, so the difference between VEGs and OMNs became clearer.

In another Brazilian study conducted by De Biasi et al., ${ }^{25}$ blood samples were collected from 76 individuals - both males and females - divided into four different diet groups: OMNs, lacto-ovo vegetarians, lacto vegetarians, and vegans. Significant differences were reported for TC, LDL-C, and TG levels among the samples. Higher levels were reported by OMNs, with decreased levels for VEGs as animal products were restricted, and the lowest levels being reported by vegans. The vegetarian diet was associated with lower levels of TG, TC, and LDL-C as compared to the diet of OMNs.

Table 3 - Framingham Risk Score prediction of coronary heart disease over a period of 10 years for women and men.*

\begin{tabular}{|c|c|c|c|c|}
\hline Women & VEG $n=27$ & SVEG $n=8$ & OMN $n=11$ & $p$ value \\
\hline LDL-based average risk of CHD\% & $1.44 \pm 1.21$ & $1.63 \pm 1.06$ & $2.36 \pm 2.42$ & 0.241 \\
\hline TC-based average risk of CHD\% & $1.44 \pm 1.28$ & $1.5 \pm 1.06$ & $2.09 \pm 1.64$ & 0.399 \\
\hline LDL-based relative risk of CHD & $0.80 \pm 0.30$ & $0.83 \pm 0.23$ & $0.99 \pm 0.41$ & 0.272 \\
\hline TC-based relative risk & $0.79 \pm 0.31$ & $0.75 \pm 0.29$ & $0.87 \pm 0.25$ & 0.658 \\
\hline Men & VEG $=19$ & SVEG $=12$ & $\mathrm{OMN}=11$ & $p$ value \\
\hline LDL-based average risk of CHD\% & $2.12 \pm 1.50$ & $3.21 \pm 2.49$ & $3.50 \pm 2.14$ & 0.068 \\
\hline TC-based average risk of CHD\% & $2.89 \pm 1.63^{*}$ & $3.58 \pm 2.15$ & $5.54 \pm 3.42 \dagger$ & $* \dagger 0.017$ \\
\hline LDL-based relative risk of $\mathrm{CHD}$ & $0.83 \pm 0.47$ & $0.87 \pm 0.31$ & $1.19 \pm 0.50$ & 0.073 \\
\hline \multirow[t]{2}{*}{ TC-based relative risk of CHD } & $0.94 \pm 0.36^{*}$ & $0.97 \pm 0.30 \dagger$ & $1.19 \pm 0.50 \%$ & $* \dagger 0.009$ \\
\hline & & & & $*+0.032$ \\
\hline
\end{tabular}

*LDL-based average risk = average risk calculated from LDL categories; TC-based average risk = average risk calculated from total cholesterol categories; LDL-based relative risk = relative risk calculated from LDL categories; TC-based relative risk = relative risk calculated from total cholesterol categories; $\mathrm{CHD}=$ coronary heart disease.

Means and percentages with different signs are significantly different from each other; $p<0.05$ (Scheffe's test for ANOVA for means and Fisher's exact test for percentages).

VEG = vegetarians, SVEG = semi-vegetarians, $\mathrm{OMN}=$ omnivorous. 
A historical cohort study was conducted in Espirito Santo $\left(\right.$ Brazil) ${ }^{26}$ to evaluate cardiovascular risk factors in VEGs and OMNs among 201 individuals. Sixty-seven VEG and $134 \mathrm{OMN}$ subjects matched for socioeconomic class, gender, age, and race were included. The mean age was 47.8 years and the mean vegetarianism was 19.1 years; a lacto-ovo VEG diet was followed by $73 \%$ of the VEGs. Blood pressure, fasting plasma glucose, total cholesterol, LDL-C, and TG were lower among VEGs $(p<0.001)$. HDL-C levels were not different between the groups. According to the Framingham algorithm, VEGs had a lower estimated cardiovascular risk $(\mathrm{p}<0.001)$.

In São Paulo, Freitas ${ }^{27}$ evaluated nutritional knowledge and the frequency of consumption of various food groups of VEGs and OMNs. One hundred fifty-three female students completed the Nutritional Knowledge Questionnaire of National Health Interview Survey Cancer Epidemiology and the Food Frequency Questionnaire (FFQ). The results indicated that $17.7 \%$ of the sample was VEG $(n=27)$. Nutritional knowledge was significantly higher among the VEG group $(p=0.0001)$. The analysis of FFQ showed that the VEGs ate significantly more $(p<0.05)$ soya beans, beans, and fruit and ate significantly less $(\mathrm{p}<0.05)$ meat, milk, pizza, snacks, sweets, soda, sugar, and coffee.

In another study, Damiao et al. ${ }^{28}$ examined the association between dietary factors and metabolic syndrome in a 7-year follow-up of Brazilians of Japanese ancestry. In 1993, a survey estimated the prevalence of diabetes in this population aged 40-79 years. Among 647 subjects studied at baseline, $394(60.9 \%)$ participated in a second survey (2000); after the exclusion of subjects with self-reported diseases, $23.4 \%(n=151)$ were included in the present analysis. Food intake was assessed by a validated foodfrequency questionnaire. At baseline, the mean ages were 56.1 and 54.7 years for men and women, respectively. Similar cumulative incidence rates of the metabolic syndrome were found in both sexes $(36.9 \%$ for men and $38.8 \%$ for women). In 1993, the mean values of blood pressure, waist circumference for men, and $2 \mathrm{~h}$ plasma glucose for both sexes were higher among subjects who developed the metabolic syndrome when compared with those who did not. Comparisons of nutrient intake between subsets of subjects who developed or did not develop the metabolic syndrome showed an association of protein intake with the syndrome only in men (964 v. $74.3 \mathrm{~g} / \mathrm{d}, \mathrm{p}<0.05)$. The odds ratios of the metabolic syndrome across tertiles of food group intake showed that, among men, the highest tertile of red meat consumption was associated with a 4.7-fold increase in the risk of developing the syndrome, after adjustments for confounders. The data raised the possibility of a role of red meat consumption in the occurrence of the metabolic syndrome in Japanese-Brazilian men.

\section{Challenges and perspectives}

The Latin American and Caribbean regions have different general characteristics as compared to other regions of the world. These peculiarities have determined certain food and nutritional problems, which require specific programs and policies. ${ }^{29}$ These regions have exhibited a marked increase in the consumption of high-energy density foods (high in fats and sugars) and a decrease in physical activity, with rising trends of sedentary lifestyles among urban populations. Social and economic progress led to a decline in infectious diseases, while higher income fostered the consumption of meats, fats and oils, and sugar and reduced the consumption of grains and legumes. The result has been a gradual increase in life expectancy at birth and a greater burden of disease linked to obesity and other nutritionrelated chronic diseases (diabetes, cardiovascular disease, certain types of cancer, and osteoporosis). The regions are currently facing the challenge of a double disease burden the unresolved problem of malnutrition caused by nutritional deficits on one hand and the steady increase in chronic disease on the other. ${ }^{30}$

On other hand, the perspectives of Latin America as a potential producer and consumer of functional foods will depend largely on the level of information and income of the population, credibility of the products, research investments, and regulatory practices. The characteristics of Latin America are diverse at the regional and sub-regional levels. Recently, in the Brazilian Congress of Cardiology, Costa et al. ${ }^{31}$ presented the results of a study evaluating the effects of "açai" fruit (Euterpe oleracea) on the blood lipid levels of the Amazonian population in the north of Brazil. It was found that levels of HDL-C increased in individuals with daily consumption of this fruit compared to those who did not consume it. Açai (Euterpe oleracea), a fruit from the Amazon region and largely consumed in Brazil, is rich in polyphenols. Approximately 10,000 tons are exported to many countries, including Japan, the United States, the Netherlands, and Italy. A great deal of evidence suggests that diets rich in polyphenols might be involved in protection against cardiovascular risk. This beneficial effect of polyphenols may be due to antioxidant action increasing the bioavailability of nitric oxide, vasodilatation, or antihypertensive properties. ${ }^{32,33}$

More investment in research is important in exploring the existing plant biodiversity, a rich source of new foods and bioactive compounds, some of which are already used for health improvement and well-being. Clinical validation of functional foods should consider functional food science concepts and the diverse cultural and genetic background of the local population. In Latin American scientific and regulatory communities, the functional foods concept has been associated with foods having health benefits beyond those of basic nutrition but is not defined officially in the emerging regulatory codes. ${ }^{34}$

\section{CONCLUSION}

From pre-historic times to the modern age, the contribution of Latin America's native population to the world's nutrition has been important. In these populations, plantbased diets have been found to be associated with lower risk factors with respect to the development of several chronic diseases as CHD, blood hypertension, diabetes mellitus, dyslipidemias, and metabolic syndrome. In spite of the opportunities offered by the richness of functional foods, the region still faces challenges due to the unresolved problem of malnutrition and the steady increase in the rate of chronic disease.

\section{REFERENCES}

1. Schardrodsky H, Escobar MC, Escobar E. Cardiovascular disease prevention. A challenge for Latin America. Circulation. 1998;98:2103-04.

2. Gibbons A. First Americans: Not mammoth hunters, but forest dwellers? Science. 1996;272:346, doi: 10.1126/science.272.5260.346.

3. Holden C. Cannibalism. Molecule shows Anasazi ate their enemies. Science. 2000;289:1663, doi: 10.1126/science.289.5485.1663b. 
4. Mariani-Constantini A, Ligabue G. Did Columbus also open the exploration of the modern diet? Nutrition Reviews. 1992;5:313-9.

5. Leakey, Richard E. A evolução da humanidade. Transl. Norma Telles. São Paulo. Ed. Universidade de Brasília, 1981, p. 198.

6. Espinoza, Waldemar. Los Incas. Economia, sociedad y estado en la era del Tahuantinsuyo. Lima. Ed. Amaru. 1997, p. 136.

7. Del Hoyo, Juan Josef. Estado del catolicismo. Politica y economia de los naturales del Perú. 1772, p. 166. CLDRHP 1 st ser., 4 (1917):161-204.

8. Baudin, Louis. El Imperio Socialista de los incas. Madrid. Ed. Rodas. 1972, p. 128

9. Pazzanesse D, Portugal OP, Ramos OL. Serum lipids levels in a Brazilian Indian population. Lancet. 1964;19:615-7, doi: 10.1016/S0140-6736(64) 90511-2.

10. Faro Netto R, Finatti AA, Monteiro P. Estudo comparativo das lipoproteínas séricas de baixa densidade (LDL) em habitantes da cidade, caiçaras do litoral norte do estado de São Paulo e indígenas da região do rio Xingu. Arq Bras Cardiol. 1966;19:331-48.

11. Ruiz L, Peñaloza D. Altitud and hypertension. Mayo Clinic Proc. 1977; 52:442-5.

12. Balke B, Snow C. Anthropological and physiological observations on Tarahumara endurance runners. Am J Phys Anthro. 1965;23:293-301, doi: 10.1002/ajpa.1330230317.

13. Groom D. Cardiovascular observations on Tarahumara Indian runners the modern Spartans. Am Heart J. 1971;81:304-14, doi: 10.1016/00028703(71)90099-8.

14. Jenkison M. The glory of the long distance runner. Nat Hist. 1972;81:54.

15. Connor, WE Cerqueira MT, Connor RW, Wallace RB, Malinow MR Casdorph HR. The plasma lipids, lipoproteins and the diet of the Tarahumara Indians of Mexico. Am J Clin Nutr. 1978;31:1131-42.

16. McMurry MP, Connor WE, Cerqueria MT. Dietary cholesterol and the plasma lipids and lipoproteins in the Tarahumara Indians. A people habituated to a low-cholesterol diet after weaning. Am J Clin Nutr. 1982;35:741-4.

17. McMurry MP, Cerqueira MT, Connor MS, Connor WE. Changes in lipid and lipoprotein levels and body weight in Tarahumara Indians after consumption of an affluent diet. New Eng J Med. 1991;325:1704-8, doi: 10.1056/NEJM199112123252405.

18. Mancilha-Carvalho JJ, Crews DE. Lipid profiles of Yanomano Indians of Brazil. Prev Med. 1990;19:66-75, doi: 10.1016/0091-7435(90)90009-9.

19. Ravussin E, Valencia ME, Esparza J, Bennet PH, Schulz LO. Effects of a traditional lifestyle on obesity in Pima Indians. Diabet Care. 1994;17:1067-74, doi: 10.2337/diacare.17.9.1067.

20. Acosta Navarro J, Prado SC, Sanchez ET, Escobedo D, Pineda Z, Tordoya $\mathrm{E}$, et al. Blood pressure, blood lipids and other biochemical parameters among vegetarian, semi-vegetarian and omnivorous Peruvians. The Lima Study. JACC. 1998;31(Suppl C):373.

21. Acosta Navarro J, Prado SC, Sanchez ET, Escobedo D, Pineda Z, Tordoya E, et al. Pressão sanguínea, perfil lipídico e outros parâmetros bioquímicos entre peruanos vegetarianos, semi-vegetarianos e onívoros. O Estudo Lima. Annais Paulist Med Cir. 1998,125:87-101.

22. Mezzano D, Muñoz X, Martínez C, Cuevas A, Panes O, Aranda E, et al. Vegetarians and cardiovascular risk factors: hemostasis, inflammatory markers and plasma homocysteine. Thromb Haemost. 1999;81:913-7.

23. Acosta Navarro JC, Prado SC, Guimarães G, Martins M, Caramelli B. Vegetarians and semi-vegetarians are less exposed to cardiovascular risk factors. Int J Atheroscler 2006;1:48-54.

24. Acosta-Navarro J, Caramelli B. Vegetarians from Latin America. Am J Cardiol. 2010;105:902, doi: 10.1016/j.amjcard.2009.10.031.

25. De Biase SG, Fernandes SF, Gianini RJ, Duarte JL. Vegetarian diet and cholesterol and triglycerides levels. Arq Bras Cardiol. 2007;88:35-9, doi: 10.1590/S0066-782X2007000100006.

26. Teixeira RC, Molina MC, Zandonade E, Mill JG. Risco cardiovascular em vegetarianos e onívoros: um estudo comparativo. Arq Bras Cardiol. 2007;89:237-44, doi: 10.1590/S0066-782X2007001600005.

27. Freitas EC, Alvarenga MS, Scagliusi FB. Avaliação do conhecimento nutricional e freqüência de ingestão de grupos alimentares em vegetarianos e não vegetarianos. Rev Bras Nutr Clin. 2006;21:267-72.

28. Damião R, Castro TG, Cardoso MA, Gimeno SG, Ferreira SR. Dietary intakes associated with metabolic syndrome in a cohort of Japanese ancestry. Br J Nutr. 2006;96:532-8.

29. Rivera JA, Barquera S, González-Cossío T, Olaiz G, Sepúlveda J. Nutrition transition in Mexico and in other Latin American countries. Nutr Rev. 2004;62(7 Pt 2):S149-57, doi: 10.1111/j.1753-4887.2004.tb00086.x.

30. Torún B. [Proteins and amino acids: features and fulfillment of requirements with Latin American diets]. Arch Latinoam Nutr. 1988;38:483-505.

31. Costa ES, Rodrigues JM, Pereira WE. Comportamento de fatores de risco modificáveis para ateroesclerose em Amazónidas qu utilizam o açai (Euterpe oleracea) na alimentação diária. Arq Bras Cardiol. 2007; 89(suppl):199.

32. Rocha AP, Carvalho LC, Sousa MA, Madeira SV, Sousa PI, Tano T, et al. Endothelium-dependent vasodilator effect of Euterpe oleracea Mart. Açaí extracts in mesenteric vascular bed of the rat. Vascular Pharmacology. 2007;46:97-104, doi: 10.1016/j.vph.2006.08.411.

33. Sosnowska J, Balslev H. American palm ethnomedicine: A meta-analysis. J Ethnobiol Ethnomed 2009;5:43, doi: 10.1186/1746-4269-5-43.

34. Lajolo FM. Functional foods: Latin American perspectives. Br J Nutr. 2002;88(suppl):S145-S150, doi: 10.1079/BJN2002679. 